\title{
Basic concepts in understanding recovery of function in vestibular reflex networks during vestibular compensation
}

\section{Kenna D. Peusner*, Mei Shao, Rebecca Reddaway and June C. Hirsch}

Department of Anatomy and Regenerative Biology, George Washington University School of Medicine, Washington, DC, USA

Edited by:

Pierre-Paul Vidal, Universite Rene

Descartes/CNRS, France

\section{Reviewed by:}

Pamela Tridandapani Bhatti, Georgia

Institute of Technology, USA

Hans Straka, Ludwig Maximilian

University of Munich, Germany

\section{*Correspondence:}

Kenna D. Peusner, Department of Anatomy and Regenerative Biology, George Washington University School of Medicine, Washington, DC, USA. e-mail: anakdp@gwumc.edu
Unilateral peripheral vestibular lesions produce a syndrome of oculomotor and postural deficits with the symptoms at rest, the static symptoms, partially or completely normalizing shortly after the lesion due to a process known as vestibular compensation. The symptoms are thought to result from changes in the activity of vestibular sensorimotor reflexes. Since the vestibular nuclei must be intact for recovery to occur, many investigations have focused on studying these neurons after lesions. At present, the neuronal plasticity underlying early recovery from the static symptoms is not fully understood. Here we propose that knowledge of the reflex identity and input-output connections of the recorded neurons is essential to link the responses to animal behavior. We further propose that the cellular mechanisms underlying vestibular compensation can be sorted out by characterizing the synaptic responses and time course for change in morphologically defined subsets of vestibular reflex projection neurons. Accordingly, this review focuses on the perspective gained by performing electrophysiological and immunolabeling studies on a specific subset of morphologically defined, glutamatergic vestibular reflex projection neurons, the principal cells of the chick tangential nucleus. Reference is made to pertinent findings from other studies on vestibular nuclei neurons, but no comprehensive review of the literature is intended since broad reviews already exist. From recording excitatory and inhibitory spontaneous synaptic activity in principal cells, we find that the rebalancing of excitatory synaptic drive bilaterally is essential for vestibular compensation to proceed. This work is important for it defines for the first time the excitatory and inhibitory nature of the changing synaptic inputs and the time course for changes in a morphologically defined subset of vestibular reflex projection neurons during early stages of vestibular compensation.

Keywords: vestibular nuclei neurons, unilateral vestibular ganglionectomy, synaptic transmission, vestibular reflex activity, chick tangential nucleus, whole-cell patch-clamp recording, spontaneous synaptic activity, immunolabeling with confocal imaging

\section{INTRODUCTION}

The classical three-neuron vestibular reflex pathways originate in the vestibular end organs where highly tuned sensors for head and body motion generate and transmit signals to the dendrites of first-order bipolar vestibular ganglion cells whose axons transmit signals to subsets of vestibular nuclei neurons which are distributed in the brainstem. Second-order vestibular nuclei neurons participating in the reflex pathways signal third-order, cranial, and spinal motor neurons, which control gaze, posture, and balance. Altogether, there are three major vestibular reflex pathways regulating eye movements and balance essentially without involving cortical structures (Wilson and Maeda, 1974). The vestibuloocular reflex (VOR) regulates the six extrinsic eye muscles to maintain gaze during head movements, the vestibulocollic reflex (VCR) controls the neck muscles to support the head during movements, and the vestibulospinal reflex (VSR) controls the muscles of the body and limbs to maintain posture and balance. In addition, some of the vestibular nuclei neurons whose axons project to the oculomotor nuclear complex in the medial longitudinal fasciculus
(MLF) have collaterals that descend to cervical spinal cord, making them vestibuloocular collic (VOC) reflex neurons (Isu et al., 1988; Minor et al., 1990), which likely coordinate movements of the head and eyes. Other neurons may contribute to the simple threeneuron reflexes, but these neurons by themselves can perform the basic reflex activities (McCrea et al., 1987). The phylogenetically old vestibular system is highly conserved during evolution (e.g., Wallman et al., 1982), perhaps due to the critical role that the vestibular reflexes plays in survival of the organism confronted by environmental challenges.

Unilateral damage to the peripheral vestibular system precipitates a complex and debilitating syndrome of oculomotor and balance deficits which include nystagmus, roll head tilt, and flexion/extension of the lower extremities (Aldrich and Peusner, 2002; Shao et al., 2009). Depending on species, the symptoms at rest, known as the static symptoms, partially or completely normalize during the first week after the lesion (Smith and Curthoys, 1989) due to a process called vestibular compensation (for review, see Halmagyi et al., 2010). In addition to the static symptoms, dynamic 
symptoms are observed during movements and these generally take weeks-to-months to recover, if at all (Curthoys and Halmagyi, 1995; Newlands et al., 2005). Both the static and dynamic symptoms are thought to result from deficits in the vestibular sensorimotor reflexes. Considerable experimental evidence indicates that changes in the vestibular sensorimotor reflexes after lesions involve functional reorganization of neurons within broadly distributed regions of the nervous system besides the vestibular nuclei, including the cerebellum, inferior olivary nucleus, spinal cord, and visual system (for review, see Llinas and Walton, 1979; Dieringer, 1995). For more than 100 years, experiments have been performed on diverse structures in the central nervous system from different vertebrate species without gaining a comprehensive view of the process of vestibular compensation. At present, it is well established that the vestibular nuclei must be intact for recovery to occur (Spiegel and Demetriades, 1925; Precht et al., 1966), underscoring a critical role for these neurons in compensation. Therefore, the preponderance of research on vestibular compensation has been focused on studying the intrinsic membrane properties (e.g., Serafin et al., 1991a,b; Johnston et al., 1994; Beraneck et al., 2003, 2004; Shao et al., 2009; for review, see Eugène et al., 2011) and responses of vestibular nuclei neurons to different stimuli after lesions (Goto et al., 2000, 2001; Shao et al., 2012). Since only a fraction of vestibular nuclei neurons function as vestibular reflex projection neurons, and their responses to the lesion depend on which vestibular reflex they participate in, we propose that it is critical to determine the reflex nature of the recorded neurons and to average data selectively from neurons participating in the same reflex pathway. We further propose that knowledge of the reflex identity of the recorded neurons is essential for linking the neuronal responses to animal behavior. Finally, we propose that the cellular mechanisms underlying vestibular compensation can be sorted out by studying the postsynaptic responses of morphologically identified subsets of vestibular reflex projection neurons after stimulating specific inputs, and characterizing the time course for change in these synaptic interactions after lesions.

The fundamental rationale behind this approach resides with the discovery that subsets of vestibular nuclei neurons with different axonal projections generate diverse spike discharge patterns (Goldberg, 2000; Sekirnjak and du Lac, 2006; Gottesman-Davis et al., 2011; Kolkman et al., 2011), and release different neurotransmitters (Spencer et al., 1989; Takazawa et al., 2004; Gittis and du Lac, 2007), with glutamate, GABA, and glycine predominating. In addition, in other sensory systems a neuron's response to deafferentation is tightly linked to its role in the network (e.g., Francis and Manis, 2000; Li et al., 2009; Zhou et al., 2009). Accordingly, we propose that different subsets of vestibular reflex projection neurons, which are distinguished by key morphological features including their inputs, outputs, neurotransmitter phenotype, and/or neuron morphology, should be recorded from after lesions and then analyzed as separate, independent groups. In most vestibular compensation studies, this approach is avoided because most vestibular nuclei lack an architectural organization of its neurons (i.e., lamination) and its neurons lack distinctive morphologies related to either axonal output, as found for cortical pyramidal cells (Romand et al., 2011), or to synaptic inputs as described for cochlear nuclei neurons (for review, see Hackney,
1987). Accordingly, it is a major challenge to relate the morphology of vestibular nuclei neurons to their functional responses so that single neuron function in a behaving animal can be defined. However, many landmark discoveries in biomedical research have been rendered by integrating disciplines. For example, bridging structural and functional approaches vastly improved our understanding of signal processing in the central auditory system (see Feng et al., 1994; Ostapoff et al., 1994), and contributed to elucidate the role of the hippocampus in memory processing (see Cossart et al., 2006), to name a few.

\section{STRUCTURE/FUNCTION STUDIES ON THE VESTIBULAR NUCLEAR COMPLEX}

Classically, the vestibular nuclear complex consists of four main vestibular nuclei: lateral, medial (MVN), superior, and descending (Büttner-Ennever, 1992), with each of them containing a wide range of neuron subsets with discrete to widely diffuse axonal projections. In addition to vestibular reflex projection neurons, the vestibular nuclei contain neurons which project to diverse cortical sites via thalamic relays to participate in the conscious awareness of motion, spatial orientation, and navigation (Highstein and Holstein, 2006; Dieterich and Brandt, 2008). Other vestibular nuclei neurons project to the ipsilateral or contralateral vestibular nuclei (Malinvaud et al., 2010), nucleus prepositus hypoglossi (McCrea and Baker, 1985; Kolkman et al., 2011), cerebellar flocculus (Highstein and Holstein, 2006), parabrachial nucleus (McCandless and Balaban, 2010), or to multiple brainstem nuclei regulating sympathetic outflow (Holstein et al., 2011). Still other vestibular nuclei neurons function as local circuit interneurons (Highstein and Holstein, 2006; Popratiloff and Peusner, 2011), or participate in the polysynaptic VOR pathways (Chen-Huang and McCrea, 1998).

In mammals, the MVN is by far the largest and most extensively studied of the four classical vestibular nuclei. MVN neurons involved in the mammalian VOR form diverse subsets, with some of them forming glycinergic inhibitory projections to the ipsilateral abducens nucleus (MVN/ABi; Spencer et al., 1989) while others contribute glutamatergic excitatory inputs to the contralateral abducens nucleus (MVN/ABc; Büttner-Ennever, 1992; Straka and Dieringer, 1993; Straka et al., 2005), with both subsets controlling horizontal eye movements. Other VOR neurons in the MVN project to the contralateral oculomotor and trochlear nuclei to regulate vertical eye movements. MVN neurons involved in the VOR tend to concentrate at rostral levels of the nucleus (Him and Dutia, 2001), and disperse mediolaterally primarily in the ventrolateral, magnocellular portion of the MVN (Sekirnjak and du Lac, 2006).

From electrophysiological studies performed on whole animals and preparations of the whole brainstem or brain slices primarily obtained from mammals, several popular catalogs of vestibular nuclei neurons have emerged. In whole animals, type I and type II neurons are distinguished by their activation on ipsilateral or contralateral head rotation (Precht et al., 1966; Sadeghi et al., 2010), vestibular only (VO) neurons are identified by their responses to passive head rotations in the ipsilateral direction (Cullen et al., 2003; Beraneck et al., 2007), and position-vestibular pause (PVP) neurons are identified by their monosynaptic responses to primary vestibular fibers, ability to encode horizontal head velocity during 
rotation, and responses to eye movements without head movements (Beraneck and Cullen, 2007). In fact, most vestibular nuclei neurons participating in the VOR fall into the category of PVP neurons, which includes both type I and type II neurons (Cullen et al., 2003). VO neurons also include type I and type II neurons as well as vestibulospinal, vestibulofastigial, and vestibulothalamic neurons (Sadeghi et al., 2011). In brain slices, the most popular catalog of vestibular nuclei neurons is the type A and type B neurons, which are distinguished by action potential waveform (Him and Dutia, 2001). Regarding neurotransmitter phenotype, most type A neurons are GABAergic, while type B neurons can be glutamatergic, GABAergic, or glycinergic (Takazawa et al., 2004; Bagnall et al., 2007). Concerning axonal projections, type B neurons in the MVN are diversified with some of them projecting to the contralateral oculomotor nucleus (Sekirnjak and du Lac, 2006) while others represent floccular target neurons (Sekirnjak et al., 2003), to name a few. It is interesting that the percentage of MVN type A and type $B$ neurons is subject to change during development (for review, Eugène et al., 2011) and after lesions (Beraneck et al., 2003, 2004). Clearly, each catalog of these functional subsets lacks homogeneity in their input-output connections and neurotransmitter phenotype.

\section{CHICKEN TANGENTIAL NUCLEUS AS A MODEL FOR VESTIBULAR COMPENSATION STUDIES}

Like mammals, birds have an interstitial nucleus of the vestibular nerve, called the tangential nucleus in avians. In the chicken, the tangential nucleus is a major vestibular nucleus, containing about 350 neurons and 3-neuron classes. Principal cells compose the vast majority (80\%; Peusner and Morest, 1977), and display large oval, glutamatergic cell bodies $(30-35 \mu \mathrm{m})$ aligned in rows between the incoming primary vestibular fibers near the lateral surface of the medulla oblongata (Peusner and Morest, 1977; Peusner and Giaume, 1997; Popratiloff and Peusner, 2011; Figure 1). Furthermore, the principal cell bodies are readily distinguished from other neurons by their large cell body size and oval shape in simple stains such as MAP2 (Peusner and Morest, 1977; Popratiloff and Peusner, 2007). The striking morphology of the principal cells is retained after unilateral vestibular ganglionectomy (UVG; Aldrich and Peusner, 2002). Thus, unlike most vestibular nuclei, the tangential principal cells conform to a simple architectural pattern, and they display distinctive morphologies which make them readily distinguishable from other vestibular nuclei neurons in the region. Primary vestibular fibers form distinctive terminals in the tangential nucleus, with the largest-diameter fibers, or "colossal fibers," forming the large "spoon-shaped" terminals which encompass about $10 \%$ of the hatchling principal cell body in a one-to-one relationship (Peusner, 1984; Figure 1). In contrast, the small-diameter primary vestibular fibers form small terminals primarily on dendrites in the tangential nucleus (Cox and Peusner, 1990a; Popratiloff et al., 2004; Popratiloff and Peusner, 2007). Combined biocytin-labeling of the primary vestibular fibers with synaptotagmin-1 (SYT-1) labeling of terminals reveal that about $24 \%$ of synaptic terminals in the tangential nucleus originate from the primary vestibular fibers (Popratiloff et al., 2004). Spoon terminals degenerate 1-3 days after UVG, while the primary vestibular fibers degenerate by 7 days (Aldrich and Peusner, 2002). GABA

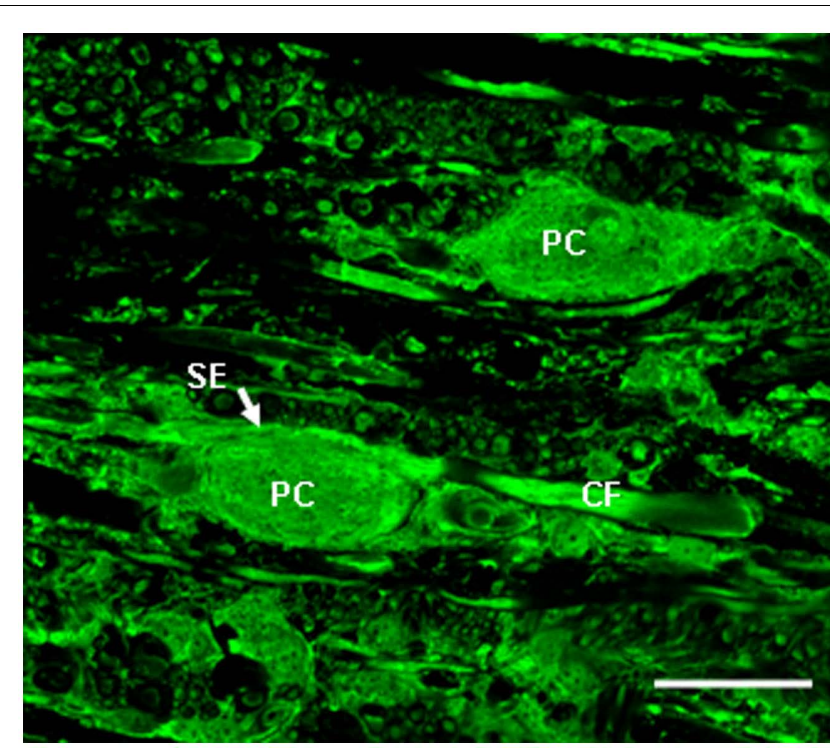

FIGURE 1 | High power confocal image $(60 x)$ of a transverse section of the medulla oblongata showing glutamate immunolabeling in the tangential nucleus of the hatchling chicken (H5). Glutamate antibody labels the vestibular fibers, including the colossal vestibular fibers (CF) and principal cell bodies (PC) in the tangential nucleus. SE, spoon ending formed on the principal cell body by a colossal fiber. Scale bar, $25 \mu \mathrm{m}$. Adapted from Popratiloff and Peusner (2011)

and glycine-positive terminals show distinct subcellular termination patterns in the tangential nucleus with greater than $50 \%$ of SYT-1-labeled terminals GABA-positive and about one-third expressing glycine (Popratiloff and Peusner, 2011).

The three semicircular canals form discrete and separate projections in the chicken tangential nucleus (Cox and Peusner, 1990a), while utricular and saccular fibers show little overlap but share common regions with the canal afferents. After electrical stimulation of individual vestibular nerve branches, the pattern of canal and otolith convergence onto vestibular nuclei neurons has been described in detail in the frog (Straka et al., 2002). In mammals, primary vestibular fibers with regular spike discharge tend to contact VOR neurons, while those with irregular-discharge pattern primarily contact VOC neurons (Highstein et al., 1987; Boyle et al., 1992). Besides labyrinthine inputs, tangential principal cells receive inputs from neurons originating in high cervical spinal cord (C1-C2; Peusner, 1984; Gross, 1985; Cox and Peusner, 1990b), the cerebellar flocculus, and contralateral MVN (Cox and Peusner, 1990b). Thus, like most vestibular nuclei, the tangential nucleus is not a simple relay center, but represents a site processing convergent, multimodal inputs.

Most principal cell axons course medially without producing collaterals in the tangential nucleus and enter the contralateral MLF to contact neurons in the oculomotor, trochlear, or abducens nucleus. Principal cells innervating the abducens nucleus may have collaterals descending to cervical spinal cord (Figure 2), while other principal cells send their axons directly to cervical spinal cord (Cox and Peusner, 1990b). In consideration of the massive output to the oculomotor, trochlear, and abducens nuclei, 


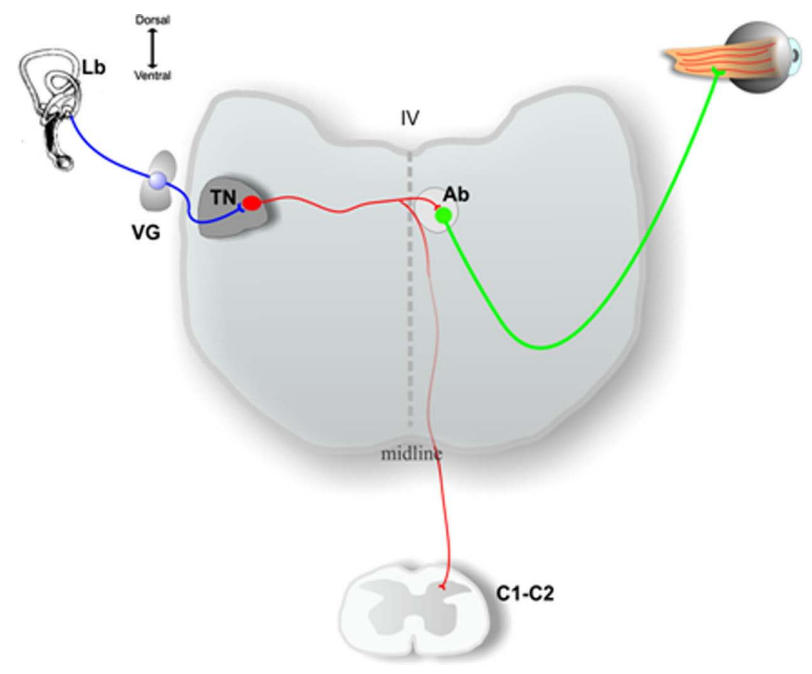

FIGURE 2 | Schematic drawing of a transverse section of the medulla oblongata at the level of the inner ear (Lb) and at the level of high cervical spinal cord (C1, C2), showing some of the output pathways of axons of the principal cells in the chick tangential nucleus (TN). See the text for a more complete description. VG, vestibular ganglion; Ab, abducens nucleus; IV, fourth ventricle. Adapted from Shao et al. (2008).

tangential principal cells in the chicken conform most closely to the mammalian MVN neurons participating in the VOR, leading to the hypothesis that the chicken tangential nucleus may represent a laterally displaced fraction of vestibular reflex projection neurons which fail to consolidate with the more medially situated MVN (Gottesman-Davis and Peusner, 2010). Horseradish peroxidase (HRP) injections restricted to the cervical spinal cord reveal that large numbers of principal cells label retrogradely with HRP, lending support to the hypothesis that many principal cells are VOC or VCR neurons (Cox and Peusner, 1990b). Thus, all of the principal cells of the chicken tangential nucleus are glutamatergic, second-order vestibular reflex projection neurons with distinct morphology (Popratiloff and Peusner, 2011), and they participate in the VOR, VCR, and/or VOC pathways (Wold, 1978; Evinger and Erichsen, 1986; Labandeira-Garcia et al., 1989; Cox and Peusner, 1990b; Petursdottir, 1990; Gottesman-Davis and Peusner, 2010).

\section{THE HATCHLING CHICKEN AS A MODEL FOR VESTIBULAR COMPENSATION STUDIES}

Although adults recover from brain lesions, they often produce irreversible deficits in brain function after damage (Dobkin, 2000). In contrast, children display a higher degree of recovery from brain damage indicating greater brain plasticity (Kaga, 1999). Accordingly, we propose that progress in understanding vestibular compensation may be accelerated by studying young brains, so our experiments are performed on the hatchling chicken. The hatchling's vestibular system matures precociously, since they can stand and feed within hours of birth (Shao et al., 2006a). When a leftsided UVG is performed on 4-day old hatchlings (H4), the majority of animals show signs of recovery starting at 3 days after UVG when they can stand, eat, and drink (Aldrich and Peusner, 2002; Shao et al., 2009, 2012). However, some subjects do not start to recover by 3 days, despite receiving similar surgical and postsurgical treatment (Shao et al., 2009, 2012). In fact, about $20 \%$ of patients who undergo surgery involving unilateral vestibular deafferentation fail to recover completely and exhibit persistent postural and dynamic reflex deficits (for review, see Badke et al., 2002; Halmagyi et al., 2010). Thus, the chicken offers an important animal model to investigate the mechanisms underlying vestibular compensation and the failure to compensate (Shao et al., 2009, 2012). Recovery from the static symptoms after UVG usually requires several additional days compared to UL. Therefore, an advantage of UVG over UL is an expanded time course to sort out the critical events. In addition, UVG produces a more predictable experimental model than UL because all of the primary vestibular fibers degenerate centrally after UVG (Aldrich and Peusner, 2002), whereas it is questionable to what extent the primary vestibular fibers and their terminals survive after UL, and for how long (Jensen, 1983; Sirkin et al., 1984; Li et al., 1995; Sadeghi et al., 2009). It is interesting that some investigators propose that the inactivation of primary vestibular fibers alone is sufficient to induce the observed behavioral deficits, regardless of whether the primary vestibular fibers degenerate in the brainstem (see Goto et al., 2002).

\section{CHICKEN VESTIBULAR REFLEXES DURING VESTIBULAR COMPENSATION}

After emerging from the eggshell, the chicken's environment and consequently its behavior change dramatically, since the chicken must begin to respond to angular and linear acceleration to maintain appropriate posture and balance for eating, drinking, and movements necessary to its survival (Rogers, 1995). These behaviors are mediated primarily by the vestibular system, although proprioceptive and visual inputs are critically involved in assisting the vestibular system to perform these basic functions under normal conditions (for review, see Llinas and Walton, 1979). Thus, it stands to reason that after vestibular deafferentation, proprioceptive, and visual inputs will be recruited early on to sustain the damaged vestibular-mediated networks. Standard ethological methods have been applied to characterize the behaviors associated with vestibular function, dysfunction, and compensation after lesions, and they provide a general evaluation of vestibular reflex activity (frog, Flohr and Precht, 1981; chicken, Heaton, 1975; Aldrich and Peusner, 2002). However, the tests do not conclusively identify dysfunction in one particular vestibular reflex. For example, tests of locomotion and balance measure both VSR and VCR function. Nonetheless, ethological tests offer a good starting point to define an approximate time course for behavioral recovery in vestibular reflex function after lesions. Below, some results from behavioral testing are presented to characterize the VSR, VCR, and VOR in hatchling chickens $1 \mathrm{~h}$ to 56 days after UVG, when surgery is performed on 4-day-old hatchlings (Figure 3; for additional details, see Aldrich and Peusner, 2002).

\section{TESTING THE VSR}

Tests of VSR function include standing, locomotion and balance, and the righting reflex. Within 4-6h after UVG, the operated hatchlings recover consciousness, are vocal, and ready to feed, but they cannot stand due to increased flexor or extensor muscle 


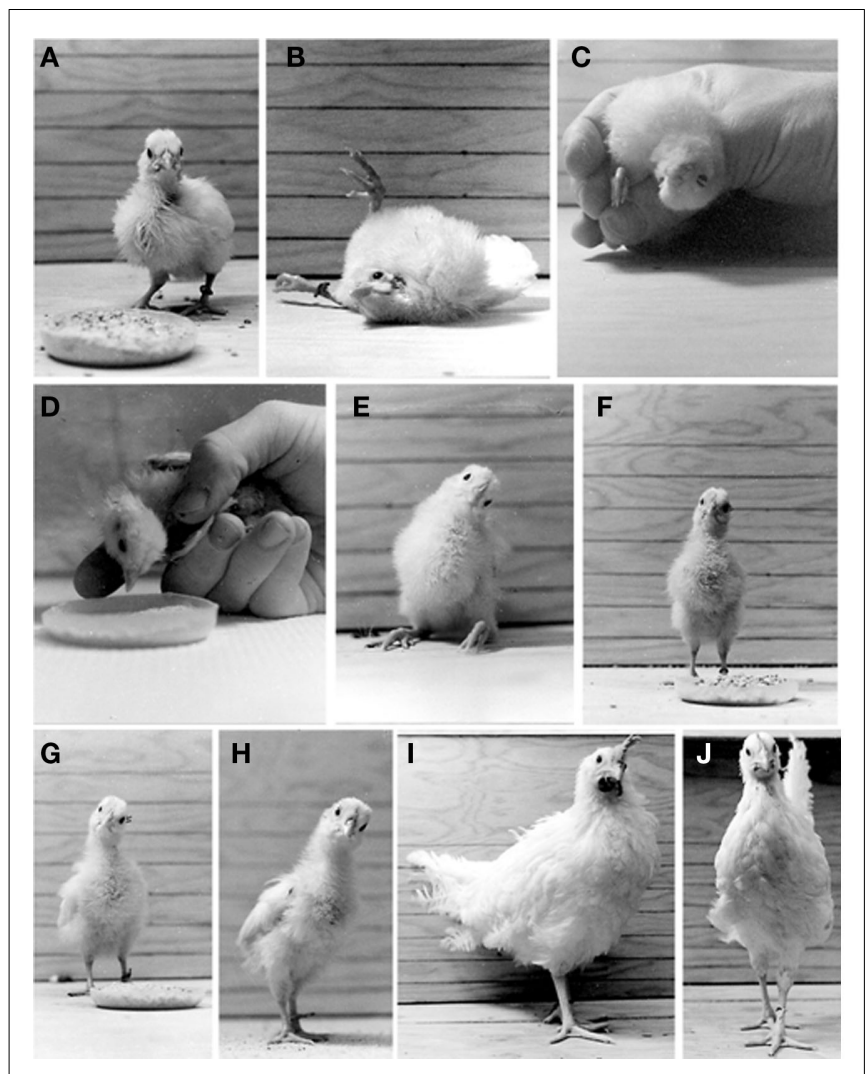

FIGURE 3 | Behaviors observed in the normal chickens $(A, J)$ and in operated hatchings which underwent a left UVG at H4 (B-I). (A) Normal 5-day-old hatchling. (B) One hour after UVG, flexion/extension of the lower extremities and extensive roll head tilt are observed. (C) Twelve hours after UVG, the operated hatchlings exhibit $180^{\circ}$ roll head tilt. (D) One day after UVG, the operated hatchlings exhibit a $90^{\circ}$ roll head tilt. (E) Three days after UVG, the operated hatchlings can stand without assistance for brief periods. (F) Three to 4 days after UVG, the operated hatchlings can stand without assistance for long periods. (G) Eight days after UVG, the operated hatchlings score near normal in the locomotion and balance tests. $\mathbf{( H , I ) ~ F o u r t e e n ~ a n d ~} 56$ days after UVG, respectively, a $30^{\circ}$ roll head tilt to the left persists. (J) Sham-operated chicken 56 days after surgery. Note the absence of roll head tilt. Adapted from Aldrich and Peusner (2002).

tone in the lower extremities which does not subside until 2 days after UVG (Figures 3B-E). By 3-4 days after UVG, most operated hatchlings can stand and peck at food without assistance for extended periods (Figure 3F). Altogether, the operated hatchlings show reduced weight gain during the first 2 weeks after UVG due to difficulties in feeding and drinking, but by 56 days after UVG there is no difference in weight between the operated and control animals. The dynamic symptoms associated with locomotion and balance have been studied by placing the operated animals in an enclosure containing chick feed to encourage pecking (Heaton, 1975). Operated hatchlings are ranked according to their ability to maintain posture, sequential foot movements, goal orientation of locomotion, and to stand or walk without falling. When operated hatchlings are placed on a table immediately after UVG, they roll toward the lesion side. Locomotion and balance scores steadily improve and return to normal over 9 days after UVG. The righting reflex is tested by placing the animal on its back, allowing time for it to stand, and counting the number of successes from multiple trials (Aldrich and Peusner, 2002). The righting reflex also takes 9 days to return to normal, with the reflex toward the lesion side less brisk and agile than that toward the intact side. Thus, these ethological tests indicate that VSR function recovers to near normal levels over a period of 9 days.

\section{TESTING THE VCR}

Tests for VCR function include roll and yaw head tilt, startle reflex, hood test, and the lift and drop test. Roll head tilt is the lateral deviation of the head and neck in the coronal plane. While most static symptoms disappear in operated hatchling, a $30^{\circ}$ roll head tilt persists throughout the 56 days of the study (Aldrich and Peusner, 2002; Figures 3E-I). This behavior is measured by drawing a line through both eyes in photographs and determining the angle formed by the line with horizontal lines on the enclosure walls (Figure 3). Yaw head tilt is the flexion of the head and neck around a vertical axis. Up to 8 days after UVG, yaw head tilt is about $45^{\circ}$ toward the lesion side, and then disappears. The startle reflex appears shortly after hatching and includes loud vocalizations, bilateral wing flapping, and running in response to loud auditory or threatening visual stimuli. Stumbling or falling is rarely observed in the normal hatchlings. When the startle reflex is elicited shortly after UVG, hatchlings lose head control, increase roll head tilt to $180^{\circ}$, and fall. From 7 to 21 days after UVG, a startle stimulus produces circling, walking backward, and occasional loss of head control. However, by 21 days, the operated hatchlings do not lose head control and show a typical response to the startle stimulus. At 9 days when locomotion and balance scores return to normal, the hood test is performed by placing an opaque cloth over the operated hatchling's head. Initially, during the hood test, animals lose head control, increase their roll head tilt to $180^{\circ}$, and fall. In response to the hood test at 21 days after UVG, roll head tilt increases to $90^{\circ}$ and the animals fall. Thereafter, the response decreases, so that by 56 days only half the operated hatchlings show increased head tilt, and none of the animals lose balance. For 10 days after UVG, the lift and drop tests are performed, producing dramatic loss of head control and increased roll head tilt to $180^{\circ}$. An animal that loses head control during the lift test also loses head control during the drop test. By 21 days after surgery, one-third of the operated hatchlings lose head control, and, by 28 days, the lift and drop tests usually have no effect. Roles for proprioceptive and visual inputs in early recovery of head control are suggested by the results of the hood and drop tests. During the first 9 days, multisensory inputs must assist the operated hatchlings in maintaining stability while other recovery processes are ongoing. Apparently, after consolidating the repair processes, non-vestibular sensory inputs become less vital for performing tasks of balance, since tests such as the lift and drop test no longer demonstrate a vestibular dysfunction. In summary, VCR activity substantially returns to normal levels by 3-4 weeks after UVG.

\section{TESTING THE VOR}

Test for VOR function include examining the operated hatchlings for spontaneous nystagmus, tonic eye deviation, whether the eyes are open or closed, and the ability to peck at food. Immediately 
after UVG, spontaneous nystagmus and tonic eye deviation are not detected on visual inspection. However, by $12 \mathrm{~h}$ after surgery, one-third of the animals have the left eye closed and the right eye open, while another third keep the left eye open and the right eye closed, and the remaining animals have both eyes open while awake. By 1 day after UVG, all the operated hatchlings keep both eyes open while awake. Unlike other species, oculomotor abnormalities are difficult to detect in hatchlings because $1-5^{\circ}$ amplitude saccades are generated naturally every 1-3 s (Wallman et al., 1982). Nonetheless, an impaired VOR is indicated by the difficulties in pecking at food and loss of head control during the startle reflex. Recovery of the VOR is indicated by the reappearance of head stability and resumption of normal grooming behavior which occurs between 13 and 21 days after UVG. Thus, although nystagmus is not detected on visual inspection, the hood test abnormalities which persist until at least 56 days after surgery, indicate a dysfunctional VOR. Altogether, visual input likely plays an important role over a prolonged period after UVG, since VOR deficits persist for at least 8 weeks after UVG.

In summary, like adult guinea pig (Schaefer and Meyer, 1981), mouse (Beraneck et al., 2008), and rat (Llinas and Walton, 1979; Precht, 1986), compensation for most static symptoms after unilateral vestibular deafferentation requires about 9 days in the hatchling chicken. Behavioral testing demonstrates that vestibular compensation does not produce a complete return to normal function. An untrained observer might have difficulty distinguishing between the experimental and control animals at rest 56 days after UVG, but the persistent $30^{\circ}$ roll head tilt is striking, indicating impaired vestibular reflex function in the operated animal (Figures 3I, J). Thus, recovery of function occurs in important, simple vestibular reflex activities necessary for daily life, including feeding, drinking, and walking. However, demonstrating dysfunction in vestibular reflex function in the operated animals depends only on accurate testing of their labyrinthine function, vestibular reflexes, and/or associated sensory systems participating in movements.

\section{SPONTANEOUS SYNAPTIC ACTIVITY}

Although evoked synaptic transmission is known to critically influence normal function of sensory systems, the physiological significance of spontaneous synaptic activity is more elusive. Spontaneous synaptic activity is often referred to as "background synaptic activity." Changing levels of spontaneous synaptic activity are thought to modulate overall neuronal activity, including spike firing rate (Chance et al., 2002). During development spontaneous synaptic events have been found to influence many crucial activities in excitable cells, including neurogenesis, formation of neural networks and space maps, emergence of tuning curves in the auditory system, and the expression of myogenic factors (e.g., Dallman et al., 1998; Friauf and Lohmann, 1999). In embryonic vestibular nuclei neurons, spontaneous synaptic events do not routinely reach the threshold for firing action potentials due to their small amplitude (Peusner and Giaume, 1994). However, in mature or nearly mature vestibular nuclei neurons, spontaneous synaptic activity can generate spike firing (Shao et al., 2006b). Thus, spontaneous synaptic events may provide sufficient excitatory or inhibitory synaptic drive to modulate the output of vestibular nuclei neurons. Both presynaptic and postsynaptic factors contribute to set the frequency of spontaneous synaptic events. Presynaptic factors include the number of presynaptic terminals, the probability of neurotransmitter release, and/or spike firing capability of the presynaptic neurons. The most important postsynaptic factor is the density of neurotransmitter receptor subunits at the synapse (Petralia et al., 1999). The kinetics of spontaneous synaptic events include their rise time, decay time, and amplitude of the response, which are determined primarily by the composition of the postsynaptic receptor subunits. However, synchronization of presynaptic neurotransmitter release and neurotransmitter clearance from the synaptic cleft also can affect the kinetics (e.g., Barberis et al., 2004). Recording spontaneous synaptic events provides a good tool to identify the excitatory or inhibitory nature of different synaptic inputs from diverse sources onto specific neurons. The excitatory or inhibitory nature of synaptic events is distinguished by recording at different voltages, while the glutamatergic, GABAergic, or glycinergic nature of the transmission is determined using specific neurotransmitter blocking agents. These are key features of the normal neuronal network to define so that its functional state after deafferentation can be better understood (Hanganu et al., 2001; Greenhill and Jones, 2007).

\section{SPONTANEOUS SYNAPTIC ACTIVITY AFTER UNILATERAL PERIPHERAL VESTIBULAR LESIONS}

Normal brain function requires a balance between excitatory and inhibitory inputs that converge onto neurons in the central nervous system, with imbalance producing major neurological disorders (e.g., Gajcy et al., 2010; Naylor, 2010). Unilateral vestibular deafferentation destroys the balance in vestibular nuclei neurons by removing a major excitatory input. One popular hypothesis predicts that vestibular compensation depends on the plasticity of non-primary vestibular afferents which contact vestibular nuclei neurons (see Discussion in Goto et al., 2002).

Our results show that both excitatory and inhibitory events in principal cells undergo major changes in frequency and kinetics at set times during recovery (Shao et al., 2012). The frequency of excitatory postsynaptic currents (EPSCs) increases in principal cells on the lesion side 1 day after UVG and remains elevated at 3 days after UVG only in the uncompensated chickens (Figure 4A). Increased EPSC frequency in principal cells could be related to the decreased expression of the voltage-dependent potassium channel, Kv1.2, in terminals contacting the principal cell bodies in uncompensated chickens (Shao et al., 2009). In other systems, decreased Kv1.2 is found to increase excitatory neurotransmitter release (Dodson et al., 2003). To investigate this possibility, future studies should determine the neurotransmitter phenotype of the synaptic terminals undergoing decreased Kv1.2 expression. The major change in kinetics found after UVG is slower miniature EPSC (mEPSC) decay time in principal cells on the lesion side compared to the intact side 3 days after UVG in all operated chickens. Since high levels of GluR2 subunits can generate slower kinetics (Geiger et al., 1995), and high levels of GluR4 subunits are associated with rapid AMPA receptor channels and fast desensitization ( $\mathrm{Zhu}, 2009)$, the relative expression of these two AMPA receptor subunits in principal cells on the lesion and intact sides could account for the 


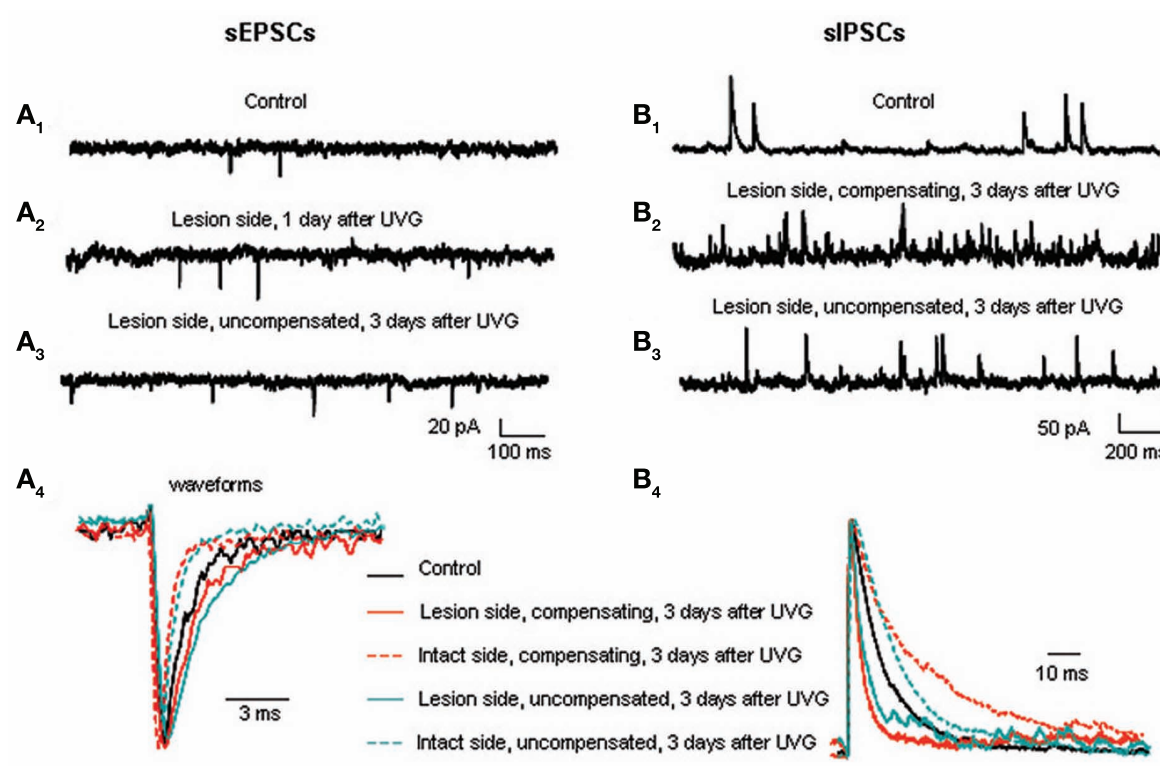

FIGURE 4 | Excitatory and inhibitory synaptic events in the principal cells before and after UVG. sEPSC frequency is higher on the lesion side $1\left(\mathbf{A}_{\mathbf{2}}\right)$ and 3 days after UVG in the uncompensated chickens $\left(\mathbf{A}_{\mathbf{3}}\right)$ compared to controls $\left(\mathbf{A}_{1}\right)$. $\left(\mathbf{A}_{4}\right)$ Superimposed and scaled mEPSC waveforms reveal that principal cells have slower decay times on the lesion side compared to the intact side in all operated animals 3 days after UVG. sIPSC frequency is higher on the lesion side in compensating $\left(\mathbf{B}_{2}\right)$ and uncompensated chickens $\left(\mathbf{B}_{3}\right) 3$ days after UVG compared to controls $\left(\mathbf{B}_{1}\right) \cdot\left(\mathbf{B}_{4}\right)$ Superimposed and scaled mIPSC waveforms show that principal cells have faster decay times on the lesion side compared to the intact side in all operated animals 3 days after UVG. Adapted from Shao et al. (2012). slower mEPSC decay time recorded after UVG. Specifically, higher levels of GluR2 and lower levels of GluR4 could result in slower mEPSC decay time in principal cells on the lesion side. Furthermore, AMPA receptors containing abundant GluR2 subunits are calcium-impermeable, so that increased GluR2 expression in principal cells on the lesion side could protect them from calcium loading which can lead to glutamate-induced cell death. In fact, none of the principal cells degenerate in compensating chickens up to 56 days after UVG (Aldrich and Peusner, 2002).

Since simultaneous changes in frequency and kinetics of spontaneous synaptic events occur within the same neuron, an approach is necessary to evaluate the overall affect of these changes on neuron excitability. Synaptic charge transfer provides this measure. Synaptic charge transfer is a measure obtained by integrating all deviations from baseline generated by spontaneous synaptic events in one neuron within a set period. Excitatory synaptic charge transfer is significantly higher in principal cells on the lesion side compared to the intact side of uncompensated chickens 3 days after UVG, and tended to be higher in principal cells on the lesion side 1 day after the lesion. However, excitatory synaptic charge transfer is balanced in principal cells on the lesion and intact side of compensating chickens 3 days after UVG. Thus, increased frequency of excitatory spontaneous synaptic activity on the lesion side may be the first step to counteract the loss of excitatory primary vestibular fiber activity, with the second step directed toward achieving balanced excitatory synaptic drive bilaterally for compensation to proceed.

Inhibitory synaptic events likewise undergo major changes during vestibular compensation, but according to a delayed time course compared to the excitatory events (Shao et al., 2012). The frequency of inhibitory postsynaptic currents (IPSCs) increases significantly in principal cells on the lesion side 3 days after UVG in both compensating and uncompensated chickens. Increased IPSC frequency is primarily due to increased GABAergic events, while the frequency of glycinergic events remains unchanged (see Table 2; Shao et al., 2012). Increased IPSC frequency is accompanied by significantly faster decay time of the events on the lesion side, so that the inhibitory synaptic charge transfer remains balanced bilaterally in compensating and uncompensated chickens 3 days after UVG (Figure 4B). Unlike the rebalancing of the excitatory synaptic drive which occurs in compensating chickens only at 3 days, rebalancing of inhibitory synaptic drive occurs in both compensating and uncompensated chickens, leading to the conclusion that balancing of inhibitory synaptic drive bilaterally is insufficient to promote vestibular compensation. Altogether, both excitatory and inhibitory synaptic drive must be balanced bilaterally for vestibular compensation to proceed.

The factors responsible for increased IPSC frequency and faster decay time in the principal cells on the lesion side have not been identified. Furthermore, the role of increased GABAergic sIPSC frequency on the lesion side after unilateral vestibular deafferentation remains uncertain. In the cat, increased number of GABA-positive neurons and GABA-labeled terminals are found throughout the vestibular nuclear complex on the lesion side 3 days after UVG (Tighilet et al., 2007), which could generate increased GABAergic IPSC frequency in vestibular nuclei neurons. In the rat, GABA neurotransmitter release from commissural 
inputs on MVN neurons increases on the lesion side shortly after UL (Bergquist et al., 2008). Faster decay time for miniature IPSCs (mIPSCs) in principal cells is consistent with finding decreased sensitivity to $\mathrm{GABA}_{\mathrm{A}}$ receptor agonists in mammalian MVN neurons on the lesion side after UL (Vibert et al., 2000; Yamanaka et al., 2000). Finally, it is interesting that GABAergic mIPSCs are absent from half the principal cells on the intact side of the uncompensated chickens 3 days after UVG, suggesting that these neurons have lost GABAergic inputs. At present, there is no evidence to support the degeneration of GABAergic terminals in the tangential nucleus on the intact side after UVG. Finally, there is no evidence for changes in glycinergic mIPSC frequency in the principal cells from any experimental group after UVG, although there are significant fluctuations in amplitude and decay time of these events (Shao et al., 2012).

\section{RECAPITULATION OF THE DEVELOPMENTAL PATTERN DURING VESTIBULAR COMPENSATION}

A major hypothesis driving our vestibular compensation studies is that important developmental targets for change also play critical roles during vestibular compensation. For example, during development, a low-threshold, dendrotoxin (DTX)-sensitive, sustained outward potassium current, $I_{\mathrm{DS}}$, is expressed highly at E16 in principal cells capable of firing single action potentials, but is down-regulated after hatching when most principal cells fire spikes repetitively on depolarization (Gamkrelidze et al., 2000). Moreover, on exposure to DTX (200 nm; $\alpha$-DTX), embryonic principal cells transform from firing single spikes to repetitive spike firing (Gamkrelidze et al., 1998). Thus, the differential expression of IDS contributes to the regulation of excitability in principal cells. Based on these developmental events, we hypothesized that $I_{\mathrm{DS}}$ is up-regulated in principal cells on the intact side of uncompensated chickens 3 days after UVG when they generate single spikes on depolarization. Indeed, these principal cells express high levels of $\mathrm{I}_{\mathrm{DS}}$ compared to principal cells in controls (Shao et al., 2009).

The emergence of spontaneous synaptic activity has been studied using brain slices at E10, E13, E16, and H1, H5, and H7, critical stages for the emergence of principal cell excitability and/or vestibular reflex activity in the chicken (Peusner and Giaume, 1997; Gamkrelidze et al., 1998, 2000; Shao et al., 2003, 2004, 2006a). During development, sEPSC frequency undergoes two major increases, between E10 and E13 when excitatory events first appear in the principal cells, and during the perinatal period between E16 and H1 (Figure 5). sIPSCs frequency also undergoes a two-step developmental increase, with the first step occurring between E13 and E16 in the interval between the two excitatory surges, and the second step beginning at the tail end of the second excitatory increase at H1 (Figure 5). Both GABAergic and glycinergic events contribute to the first sIPSC developmental surge, but only GABAergic events account for the second one. At most stages investigated, GABAergic frequency is higher than all other synaptic events recorded in principal cells, except at $\mathrm{H} 1$, when sEPSC and sIPSC frequencies are similar and GABAergic and glycinergic-mediated sIPSC frequencies are equal. During vestibular compensation, the developmental pattern is repeated in that EPSC frequency increases first, followed by increased IPSC

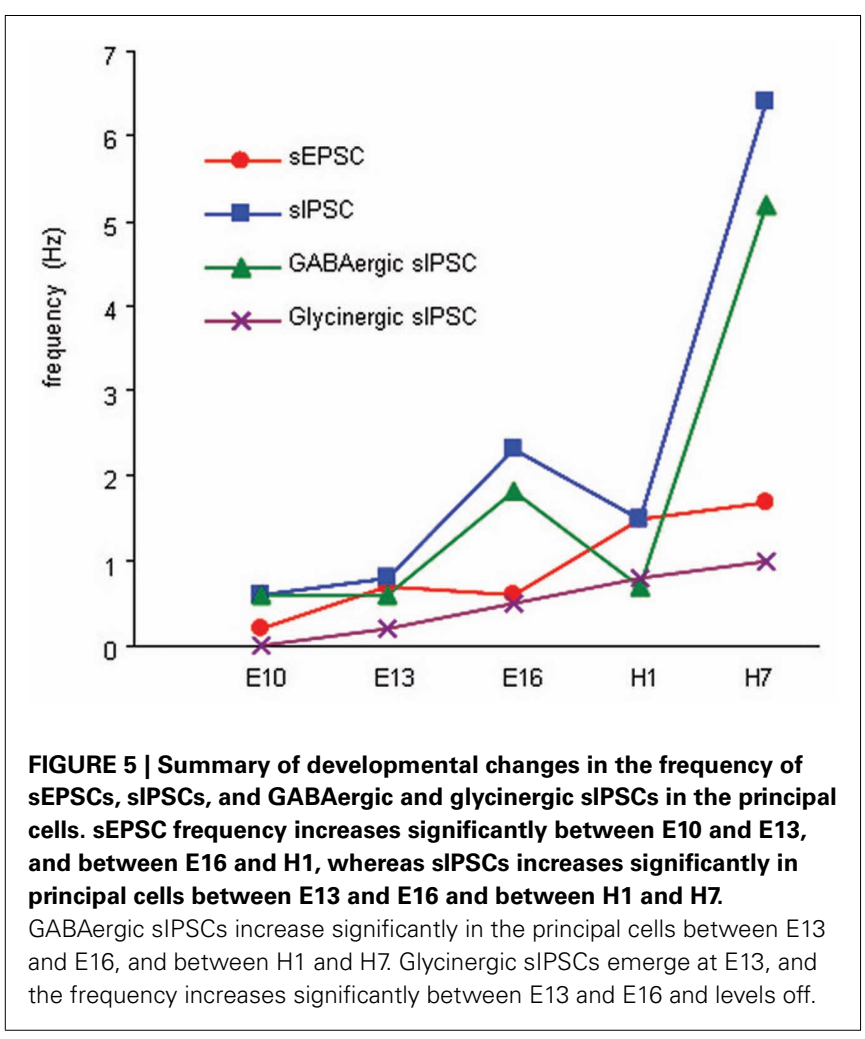

frequency. In addition, during early recovery, the frequency of GABAergic events predominates (Shao et al., 2012).

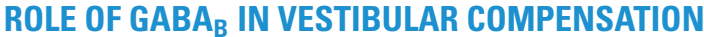

The cellular mechanisms that modulate neuronal excitability by producing changes in neurotransmitter release could play critical roles in vestibular compensation. $\mathrm{GABA}_{\mathrm{B}}$ receptors are strong candidates for this role. $\mathrm{GABA}_{\mathrm{B}}$ receptors are metabotrophic Gproteins-coupled receptors (Wojcik and Neff, 1984; Hill, 1985; Karbon and Enna, 1985) which can localize at presynaptic, postsynaptic, and extrasynaptic neuronal membranes (Kaupmann et al., 1998; Kulik et al., 2002, 2003; Lopez-Bendito et al., 2002; Koyrakh et al., 2005). GABA $\mathrm{B}$ receptors are detected in the brainstem of the human (Billinton et al., 2000), and in the rodent vestibular nuclei (Eleore et al., 2005). Both presynaptic and postsynaptic $\mathrm{GABA}_{\mathrm{B}}$ receptors are found in rodent MVN neurons using immunocytochemical (Holstein et al., 1992a,b) and electrophysiological approaches on brain slice preparations (Dutia et al., 1992; Vibert et al., 1995; Sun et al., 2002). Two types of presynaptic GABAB receptors are distinguished based on the neurotransmitter phenotype of the terminals where they are expressed. $\mathrm{GABA}_{\mathrm{B}}$ autoreceptors are located on GABAergic terminals, whereas $G_{A B A}$ heteroreceptors are positioned on non-GABAergic terminals (for review, see Bettler and Tiao, 2006) and may be activated by ambient GABA or GABA spillover from nearby GABAergic terminals

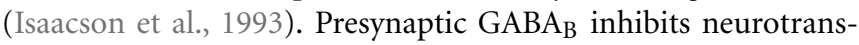
mitter release by decreasing calcium conductances, while postsynaptic $\mathrm{GABA}_{\mathrm{B}}$ modulates neuronal excitability by increasing potassium conductances (for review, see Bowery et al., 2002; Bettler 
and Tiao, 2006). To date, no $\mathrm{GABA}_{\mathrm{B}}$ receptor-mediated spontaneous or evoked postsynaptic potentials have been recorded in vestibular nuclei neurons, except for those found in embryonic principal cells of the chick tangential nucleus (E16; Shao et al., 2003).

Changes in presynaptic $\mathrm{GABA}_{\mathrm{B}}$ receptor expression could contribute to the fluctuations in GABA levels reported in the MVN (Bergquist et al., 2008), and changes in EPSC and IPSC frequencies in the tangential principal cells after UVG (Shao et al., 2012). Behavioral studies support a role for $G_{A B} A_{B}$ receptors in vestibular compensation, since baclofen, a $G_{A B A}$ agonist, decreases spontaneous nystagmus (Magnusson et al., 2000, 2002) and accelerates the recovery of the postural reflexes when injected systemically after UL (Heskin-Sweezie et al., 2010). In fact, the first direct evidence of a role for $G_{A B A B}$ receptors in vestibular compensation was obtained from extracellular recordings of spontaneous spike activity in brain slices where decreased efficacy to baclofen was found in MVN neurons on the lesion side $4 \mathrm{~h}$ after UL, with increased efficacy detected on the intact side relative to controls (Yamanaka et al., 2000). MVN neurons on the lesion side continue to show decreased efficacy to baclofen from 7 to 10 days after the lesion (Johnston et al., 2001). Other studies measuring relative gene expression indicate a rapid transient increase in $\mathrm{GABA}_{\mathrm{B}}$ on the lesion side $6 \mathrm{~h}$ after UL (Horii et al., 2003), while in situ hybridization (Eleore et al., 2005), Western blot, and immunocytochemical experiments (Zhang et al., 2005 ) indicate no change in the $\mathrm{GABA}_{\mathrm{B}}$ mRNA or protein expression on the lesion or intact sides shortly after UL. These apparently contradictory findings could result from methodological limitations (e.g., limited sensitivity of Western blot), combining data from different MVN neuron subsets, and/or the inability or failure to distinguish presynaptic and postsynaptic $\mathrm{GABA}_{\mathrm{B}}$ expression which can be differentially affected after lesions. The ongoing experiments on the chick tangential principal cells apply whole-cell patch-clamp recordings and immunolabeling combined with confocal imaging, both of which can distinguish presynaptic and postsynaptic $\mathrm{GABA}_{\mathrm{B}}$ receptor expression (Shao et al., 2011).

\section{FUTURE STUDIES TO CLARIFY THE FUNCTION OF THE VESTIBULAR REFLEX PATHWAYS DURING VESTIBULAR COMPENSATION}

Vestibular reflex testing in whole animals is an elegant approach to quantify the extent of recovery from the dynamic symptoms after peripheral vestibular lesions. In adults, VOR gain is usually close to 1.0 over the range for natural head movements made during daily life. When the VOR is tested in the adult mouse after UL using sinusoidal rotations in the dark at frequencies similar to those found for natural behaviors $(0.2-4 \mathrm{~Hz})$, the gain is reduced to 0.2 for head rotations toward the lesion side at 1 day after UL, recovers to 0.4 by 5 days, and acquires normal values 10 days after UL (Beraneck et al., 2008). In the mouse, the static symptoms which appear immediately after UL, including spontaneous nystagmus in the dark, head tilt, and postural imbalance also resolve within 10 days. Thus, the time course for recovery from certain static and dynamic symptoms after UL may overlap. Studies performed on the monkey indicate that recovery of the VOR after UL takes about a month for rotations toward the lesion side (Cullen et al., 2009; Sadeghi et al., 2010). From single unit recordings, recovery from the static and dynamic symptoms in the monkey appear to be under the influence of neck proprioceptive inputs. Indeed, subsets of vestibular nuclei neurons become responsive to neck inputs 1-3 weeks after UL, although the same or similar vestibular nuclei neurons fail to respond to the inputs in the normal monkey (Sadeghi et al., 2011). The gain of the VCR, usually 1.0, is calculated as the ratio between the amplitude of the horizontal head and turntable velocities. Thus, a fully compensated VCR has a gain of 1.0 and a head velocity $180^{\circ}$ out of phase with the turntable (Goode et al., 1999).

Vestibular reflex activity has not been quantified in whole hatchling chickens after UVG, but tests have been performed on 5-week-old hatchlings after a 5-day exposure to streptomycin at $\mathrm{H} 10$, which reduces VCR and VOR gains to zero (Goode et al., 1999, 2001). Three weeks after streptomycin exposure, VCR gain and phase recover to near normal, but VOR gain remains at half normal (Goode et al., 1999). Apparently, VCR recovers before VOR in this system. In 5-week-old normal hatchlings, VCR and VOR gains are $0.6-0.7$, with the VOR gain reaching 1.0 only in adult chickens (Goode et al., 2001). During development, VCR gains tend to be higher than VOR gains at the ages tested (Goode et al., 1999), but the age at which this reflex achieves adult values has not been established. After UVG, we expect that recovery of the VSR, VCR, and VOR likely follow different time courses due to their different central pathways and final targets. According to the rough measures provided by ethological testing, we predict that VSR will recover first, followed by recovery of VCR, and finally the VOR.

Despite a partial coincidence in timing of behavioral recovery with restoration of spontaneous spike firing in rodent MVN neurons studied in vivo, a time-locked sequence of events has not been found (Ris et al., 1997; for review, see Straka et al., 2005). Thus, behavioral recovery after unilateral vestibular deafferentation cannot be explained exclusively by changes in vestibular nucleus neurons. In fact, in the chicken, a dissociation between the whole animal behavior and in vitro electrophysiological changes in principal cells is apparent 1 day after UVG because spontaneous spike firing is symmetric in the principal cells on the lesion and intact sides at the same time that the operated chickens display severe postural deficits. The dissociation between the responses of vestibular nuclei neurons and animal behavior points to a critical role for neurons which modulate vestibular reflex activity during vestibular compensation. Nonetheless, the chicken vestibular system provides a good model to test the role of vestibular reflex projection neurons and other neurons in vestibular compensation for the reasons given in this review. Further knowledge of the neural circuitry of different subsets of vestibular reflex projection neurons, as well as brainstem, spinal cord, and cerebellar neurons interacting with them, will lead to a better understanding of this important form of brain plasticity after lesions.

\section{ACKNOWLEDGMENTS}

The authors' work related to this manuscript was supported by National Institutes of Health grant R01-DC000970 to Kenna D. Peusner. 


\section{REFERENCES}

Aldrich, E. M., and Peusner, K. D. (2002). Vestibular compensation after ganglionectomy, ultrastructural study of the tangential vestibular nucleus and behavioral study of the hatchling chick. J. Neurosci. Res. 67, 122-138.

Badke, M. B., Pyle, G. M., Shea, T., and Miedaner, J. (2002). Outcomes in vestibular ablative procedures. Otol. Neurotol. 23, 504-509.

Bagnall, M. W., Stevens, R. J., and du Lac, S. (2007). Transgenic mouse lines subdivide medial vestibular nucleus neurons into discrete, neurochemically distinct populations. J. Neurosci. 27, 2318-2330.

Barberis, A., Petrini, E. M., and Cherubini, E. (2004). Presynaptic source of quantal size variability at GABAergic synapses in rat hippocampal neurons in culture. Eur. J. Neurosci. 20, 1803-1810.

Beraneck, M., and Cullen, K. E. (2007). Activity of vestibular nuclei neurons during vestibular and optokinetic stimulation in the alert mouse. J. Neurophysiol. 98, 1549-1565.

Beraneck, M., Hachemaoui, M., Idoux, E., Ris, L., Uno, A., Godaux, E., Vidal, P. P., Moore, L. E., and Vibert, N. (2003). Long-term plasticity of ispilateral medial vestibular nucleus neurons after unilateral labyrinthectomy. J. Neurophysiol. 90, 184-203.

Beraneck, M., Idoux, E., Uno, A., Vidal, P. P., Moore, L. E., and Vibert, N. (2004). Unilateral labyrinthectomy modifies the membrane properties of contralesional vestibular neurons. J. Neurophysiol. 92, 1668-1684.

Beraneck, M., McKee, J. L., Aleisa, M., and Cullen, K. E. (2008). Asymmetric recovery in cerebellardeficient mice following unilateral labyrinthectomy. J. Neurophysiol. 100, 945-958.

Beraneck, M., Pfanzelt, S., Vassias, I., Rohregger, M., Vibert, N., Vidal, P. P., Moore, L. E., and Straka, H. (2007). Differential intrinsic response dynamics determine synaptic signal processing in frog vestibular neurons. J. Neurosci. 27, 4283-4296.

Bergquist, F., Ludwig, M., and Dutia, M. B. (2008). Role of the commissural inhibitory system in vestibular compensation in the rat. J. Physiol. 586, 4441-4452.

Bettler, B., and Tiao, J. Y. (2006). Molecular diversity, trafficking and subcellular localization of GABAB receptors. Pharmacol. Ther. 110, 533-543.

Billinton, A., Ige, A. O., Wise, A., White, J. H., Disney, G. H., Marshall, F. H., Waldvogel, H. J., Faull,
R. L., and Emson, P. C. (2000). GABA(B) receptor heterodimercomponent localisation in human brain. Brain Res. Mol. Brain Res. 77 111-124.

Bowery, N. G., Bettler, B., Froestl, W. Gallagher, J. P., Marshall, F., Raiteri, M., Bonner, T. I., and Enna, S. J. (2002). International Union of Pharmacology. XXXIII. Mammalian gamma-aminobutyric acid (B) receptors: structure and function. Pharmacol. Rev. 54, 247-264.

Boyle, R., Goldberg, J. M., and Highstein, S. M. (1992). Inputs from regularly and irregularly discharging vestibular nerve afferents to secondary neurons in squirrel monkey vestibular nuclei. III. Correlation with vestibulospinal and vestibulocular output pathways. J. Neurophysiol. $68,471-484$

Büttner-Ennever, J. A. (1992). Patterns of connectivity in the vestibular nuclei. Ann. N. Y. Acad. Sci. 656, 363-378.

Chance, F. S., Abbott, L. F., and Reyes, A. D. (2002). Gain modulation from background synaptic input. Neuron 35, 773-782.

Chen-Huang, C., and McCrea, R. A. (1998). Contribution of vestibular nerve irregular afferents to viewing distance-related changes in the vestibulo-ocular reflex. Exp. Brain Res. 119, 116-130.

Cossart, R., Petanjek, Z., Dumitriu, D., Hirsch, J. C., Ben-Ari, Y., Esclapez, M., and Bernard, C. (2006). Interneurons targeting similar layers receive synaptic inputs with similar kinetics. Hippocampus 16, 408-420.

Cox, R. G., and Peusner, K. D. (1990a). Horseradish peroxidase labeling of the central pathways in the medulla of the ampullary nerves in the chicken, Gallus gallus. J. Comp. Neurol. 297, 564-581.

Cox, R. G., and Peusner, K. D. (1990b). Horseradish peroxidase labeling of the efferent and afferent pathways of the avian tangential vestibular nucleus. J. Comp. Neurol. 296, 324-341.

Cullen, K. E., Minor, L. B., Beraneck, M., and Sadeghi, S. G. (2009). Neural substrates underlying vestibular compensation: contribution of peripheral versus central processing. J. Vestib. Res. 19, 171-182.

Cullen, K. E., Roy, J. E., and Sylvestre, P. A. (2003). "Signal processing in vestibular nuclei, dissociating sensory, motor and cognitive influences," in Levels of Perception, eds L. Harris and M. Jenkin (New York: Oxford University Press), 285-310.
Curthoys, I. S., and Halmagyi, G. M. (1995). Vestibular compensation: a review of the oculomotor, neural, and clinical consequences of unilateral vestibular loss. J. Vestib. Res. 5 , 67-107.

Dallman, J. E., Davis, A. K., and Moody, W. J. (1998). Spontaneous activity regulates calcium-dependent $\mathrm{K}^{+}$ current expression in developing ascidian muscle. J. Physiol. 511, 683-693.

Dieringer, N. (1995). 'Vestibular compensation': neural plasticity and its relations to functional recovery after labyrinthine lesions in frogs and other vertebrates. Prog. Neurobiol. 46, 97-129.

Dieterich, M., and Brandt, T. (2008). Functional brain imaging of peripheral and central vestibular disorders. Brain 131, 2538-2552.

Dobkin, B. H. (2000). Functional rewiring of brain and spinal cord after injury: the three Rs of neural repair and neurological rehabilitation. Curr. Opin. Neurol. 13, 655-659.

Dodson, P. D., Billups, B., Rusznák Z., Szûcs, G., Barker, M. C., and Forsythe, I. D. (2003). Presynaptic rat Kv1.2 channels suppress synaptic terminal hyperexcitability following action potential invasion. J. Physiol. 550, 27-33.

Dutia, M. B., Johnston, A. R., and McQueen, D. S. (1992). Tonic activity of rat medial vestibular nucleus neurones in vitro and its inhibition by GABA. Exp. Brain Res. 88, 466-472.

Eleore, L., Vassias, I., Bernat, I., Vidal, P. P., and de Waele, C. (2005). An in situ hybridization and immunofluorescence study of GABA(A) and GABA(B) receptors in the vestibular nuclei of the intact and unilaterally labyrinthectomized rat. Exp. Brain Res. 160, 166-179.

Eugène, D., Idoux, E., Beraneck, M. Moore, L. E., and Vidal, P. P. (2011). Intrinsic membrane properties of central vestibular neurons in rodents. Exp. Brain Res. 210, 423-436.

Evinger, C., and Erichsen, J. T. (1986). Transsynaptic retrograde transport of fragment $\mathrm{C}$ of tetanus toxin demonstrated by immunohistochemical localization. Brain Res. 380, 383-388

Feng, J. J., Kuwada, S., Ostapoff, E. M., Batra, R., and Morest, D. K. (1994). A physiological and structural study of neuron types in the cochlear nucleus. I. Intracellular responses to acoustic stimulation and current injection. J. Comp. Neurol. 346, 1-18.
Flohr, H., and Precht, W. (1981). Lesion-Induced Neuronal Plasticity in Sensorimotor Systems. New York: Springer-Verlag.

Francis, H. W., and Manis, P. B. (2000). Effects of deafferentation on the electrophysiology of ventral cochlear nucleus neurons. Hear. Res. 149, 91-105.

Friauf, E., and Lohmann, C. (1999). Development of auditory brainstem circuitry. Activity-dependent and activity-independent processes. Cell Tissue Res. 297, 187-195.

Gajcy, K., Lochynski, S., and Librowski, T. (2010). A role of GABA analogues in the treatment of neurological diseases. Curr. Med. Chem. 17, 2338-2347.

Gamkrelidze, G., Giaume, C., and Peusner, K. D. (1998). The differential expression of low-threshold sustained potassium current contributes to the distinct firing patterns in embryonic central vestibular neurons. J. Neurosci. 18, 1449-1464.

Gamkrelidze, G., Giaume, C., and Peusner, K. D. (2000). Firing properties and dendrotoxin-sensitive sustained potassium current in vestibular nuclei neurons of the hatchling chick. Exp. Brain Res. 134, 398-401.

Geiger, J. R., Melcher, T., Koh, D. S., Sakmann, B., Seeburg, P. H., Jonas, P., and Monyer, H. (1995). Relative abundance of subunit mRNAs determines gating and $\mathrm{Ca}^{2+}$ permeability of AMPA receptors in principal neurons and interneurons in rat CNS. Neuron 15, 193-204.

Gittis, A. H., and du Lac, S. (2007). Firing properties of GABAergic versus non-GABAergic vestibular nucleus neurons conferred by a differential balance of potassium currents. J. Neurophysiol. 97, 3986-3996.

Goldberg, J. M. (2000). Afferent diversity and the organization of centra vestibular pathways. Exp. Brain Res. 130, 277-297.

Goode, C. T., Carey, J. P., Fuchs, A. F., and Rubel, E. W. (1999). Recovery of the vestibulocollic reflex after aminoglycoside ototoxicity in domestic chickens. J. Neurophysiol. 81, 1025-1035.

Goode, C. T., Maney, D. L., Rubel, E. W., and Fuchs, A. F. (2001). Visual influences on the development and recovery of the vestibuloocular reflex in the chicken. J. Neurophysiol. 85 1119-1128.

Goto, F., Straka, H., and Dieringer, N. (2000). Expansion of afferent vestibular signals after the section of one of the vestibular nerve branches. J. Neurophysiol. 84, 581-584.

Goto, F., Straka, H., and Dieringer, N. (2001). Postlesional vestibular 
reorganization in frogs: evidence for a basic reaction pattern after nerve injury. J. Neurophysiol. 85, 2643-2646.

Goto, F., Straka, H., and Dieringer, N. (2002). Gradual and reversible central vestibular reorganization in frog after selective labyrinthine nerve branch lesions. Exp. Brain Res. 147, 374-386.

Gottesman-Davis, A., and Peusner, K. D. (2010). Identification of vestibuloocular reflex projection neurons in the developing chicken medial vestibular nucleus. J. Neurosci. Res. 88, 290-303.

Gottesman-Davis, A., Shao, M., Hirsch, J. C., and Peusner, K. D. (2011). Electrophysiological properties of morphologically-identified medial vestibular nucleus neurons projecting to the abducens nucleus in the chick embryo. Neuroscience 172, 494-509.

Greenhill, S. D., and Jones, R. S. G. (2007). Simultaneous estimation of global background synaptic inhibition and excitation from membrane potential fluctuations in layer III neurons of the rat entorhinal cortex in vitro. Neuroscience 147, 884-892.

Gross, G. H. (1985). Innervation of the complexus ("hatching") muscle of the chick. J. Comp. Neurol. 232, 180-189.

Hackney, C. M. (1987). Anatomical features of the auditory pathway from cochlea to cortex. Br. Med. Bull. 43, 780-801.

Halmagyi, G. M., Weber, K. P., and Curthoy, I. S. (2010). Vestibular function after acute vestibular neuritis. Restor. Neurol. Neurosc. 28, $37-46$.

Hanganu, I. L., Kilb, W., and Luhmann, H. J. (2001). Spontaneous synaptic activity of subplate neurons in neonatal rat somatosensory cortex. Cereb. Cortex 11, 400-410.

Heaton, M. B. (1975). Behavioral adaptation in neonatal chicks following embryonic vestibular system rearrangement. J. Exp. Zool. 194, 495-510.

Heskin-Sweezie, R., Titley, H. K., Baizer, J. S., and Broussard, D. M. (2010). Type B GABA receptors contribute to the restoration of balance during vestibular compensation in mice. Neuroscience 169, 302-314.

Highstein, S. M., Goldberg, J. M., Moschovakis, A. K., and Fernández, C. (1987). Inputs from regularly and irregularly discharging vestibular nerve afferents to secondary neurons in the vestibular nuclei of the squirrel monkey. II. Correlation with output pathways of secondary neurons. J. Neurophysiol. 58, 719-738.

Highstein, S. M., and Holstein, G. R. (2006). The anatomy of the vestibular nuclei. Prog. Brain Res. 151, 157-203.

Hill, D. R. (1985). GABAB receptor modulation of adenylate cyclase activity in rat brain slices. $\mathrm{Br}$. J. Pharmacol. 84, 249-257.

Him, A., and Dutia, M. B. (2001). Intrinsic excitability changes in vestibular neurons after unilateral deafferentation. Brain Res. 908, 58-66.

Holstein, G. R., Martinelli, G. P., and Cohen, B. (1992a). L-baclofensensitive GABAB binding sites in the medial vestibular nucleus localized by immunocytochemistry. Brain Res. 581, 175-180.

Holstein, G. R., Martinelli, G. P., and Cohen, B. (1992b). Immunocytochemical visualization of Lbaclofen-sensitive GABAB binding sites in the medial vestibular nucleus. Ann. N. Y. Acad. Sci. 656, 933-936.

Holstein, G. R., Martinelli, G. P., and Friedrich, V. L. (2011). Anatomical observations of the caudal vestibulosympathetic pathway. J. Vestib. Res. $21,49-62$.

Horii, A., Kitahara, T., Smith, P. F., Darlington, C. L., Masumura, C., and Kubo, T. (2003). Effects of unilateral labyrinthectomy on GAD, GAT1 and GABA receptor gene expression in the rat vestibular nucleus. Neuroreport 14, 2359-2363.

Isaacson, J. S., Solis, J. M., and Nicoll, R. A. (1993). Local and diffuse synaptic actions of GABA in the hippocampus. Neuron 10, 165-175.

Isu, N., Uchino, Y., Nakashima, H., Satoh, S., Ichikawa, T., and Watanabe, S. (1988). Axonal trajectories of posterior canal-activated secondary vestibular neurons and their coactivation of extraocular and neck flexor motoneurons in the cat. Exp. Brain Res. 70, 181-191.

Jensen, D. W. (1983). Survival of function in the deafferentated vestibular nerve. Brain Res. 273, 175-178.

Johnston, A. R., Him, A., and Dutia, M. B. (2001). Differential regulation of GABA(A) and GABA(B) receptors during vestibular compensation. Neuroreport 12, 597-600.

Johnston, A. R., MacLeod, N. K., and Dutia, M. B. (1994). Ionic conductances contributing to spike repolarization and after-potentials in rat medial vestibular nucleus neurones. J. Physiol. 481, 61-77.

Kaga, K. (1999). Vestibular compensation in infants and children with congenital and acquired vestibular loss in both ears. Int. J. Pediatr. Otorhinolaryngol. 49 , 215-224.

Karbon, E. W., and Enna, S. J. (1985). Characterization of the relationship between gamma-aminobutyric acid $\mathrm{B}$ agonists and transmitter-coupled cyclic nucleotide-generating systems in rat brain. Mol. Pharmacol. 27, 53-59.

Kaupmann, K., Malitschek, B., Schuler, V., Heid, J., Froestl, W., Beck, P. Mosbacher, J., Bischoff, S., Kulik, A. Shigemoto, R., Karschin, A., and Bettler, B. (1998). GABA(B)-receptor subtypes assemble into functional heteromeric complexes. Nature 396 , 683-687.

Kolkman, K. E., Moghadam, S. H., and du Lac, S. (2011). Intrinsic physiology of identified neurons in the prepositus hypoglossi and medial vestibular nuclei. J. Vestib. Res. 21 , 33-47.

Koyrakh, L., Lujan, R., Colon, J., Karschin, C., Kurachi, Y., Karschin, A., and Wickman, K. (2005). Molecular and cellular diversity of neuronal G-protein-gated potassium channels. J. Neurosci. 25, 11468-11478.

Kulik, A., Nakadate, K., Nyiri, G., Notomi, T., Malitschek, B., Bettler B., and Shigemoto, R. (2002). Distinct localization of GABA(B) receptors relative to synaptic sites in the rat cerebellum and ventrobasal thalamus. Eur. J. Neurosci. 15, 291-307.

Kulik, A., Vida, I., Lujan, R., Haas, C. A., Lopez-Bendito, G., Shigemoto, R., and Frotscher, M. (2003). Subcellular localization of metabotropic GABA(B) receptor subunits $\mathrm{GABA}(\mathrm{B} 1 \mathrm{a} / \mathrm{b})$ and $\mathrm{GABA}(\mathrm{B} 2)$ in the rat hippocampus. J. Neurosci. 23, 11026-11035.

Labandeira-Garcia, J. L., Guerra-Seijas, M. J., Labandeira-Garcia, J. A., and Jorge-Barreiro, F. J. (1989). Afferent connections of the oculomotor nucleus in the chick. J. Comp. Neurol. $282,523-534$

Li, H., Godfrey, D. A., and Rubin, A. M. (1995). Comparison of surgeries for removal of primary vestibular inputs: a combined anatomical and behavioral study in rats. Laryngoscope 105, 417-424.

Li, P., Rudolph, U., and Huntsman, M. M. (2009). Long-term sensory deprivation selectively rearranges functional inhibitory circuits in mouse barrel cortex. Proc. Natl. Acad. Sci. U.S.A. 106, 12156-12161.
Llinas, R., and Walton, K. (1979). "Vestibular compensation: a distributed property of the central nervous system," in Integration in the Nerous System, eds H. Asanuma and V. J. Wilson (Tokyo: Igaku-Shoin), 145-166.

Lopez-Bendito, G., Shigemoto, R., Kulik, A., Paulsen, O., Fairen, A. and Lujan, R. (2002). Expression and distribution of metabotropic GABA receptor subtypes GABABR1 and GABABR2 during rat neocortical development. Eur. J. Neurosci. 15, 1766-1778.

Magnusson, A. K., Lindstrom, S., and Tham, R. (2000). GABA(B) receptors contribute to vestibular compensation after unilateral labyrinthectomy in pigmented rats. Exp. Brain Res. 134, 32-41.

Magnusson, A. K., Ulfendahl, M. and Tham, R. (2002). Early compensation of vestibulooculomotor symptoms after unilateral vestibular loss in rats is related to $\mathrm{GABA}(\mathrm{B})$ receptor function. Neuroscience 111, 625-634.

Malinvaud, D., Vassias, I., Reichenberger, I., Rössert, C., and Straka H. (2010). Functional organization of vestibular commissural connections in frog. J. Neurosci. 30, 3310-3325.

McCandless, C. H., and Balaban, C. D. (2010). Parabrachial nucleus neuronal responses to off-vertical axis rotation in macaques. Exp. Brain Res. 202, 271-290.

McCrea, R. A., and Baker, R. (1985). Anatomical connections of the nucleus prepositus of the cat. $J$. Comp. Neurol. 237, 377-407.

McCrea, R. A., Strassman, A., May, E., and Highstein, S. M. (1987) Anatomical and physiological characteristics of vestibular neurons mediating the horizontal vestibuloocular reflex of the squirrel monkey. J. Comp. Neurol. 264, 547-570.

Minor, L. B., McCrea, R. A., and Goldberg, J. M. (1990). Dual projections of secondary vestibular axons in the medial longitudinal fasciculus to extraocular motor nuclei and the spinal cord of the squirrel monkey. Exp. Brain Res. 83, 9-21.

Naylor, D. E. (2010). Glutamate and GABA in the balance, convergent pathways sustain seizures during status epilepticus. Epilepsia 51, 106-109.

Newlands, S. D., Dara, S., and Kaufman, G. D. (2005). Relationship of static and dynamic mechanisms in vestibuloocular reflex 
compensation. Laryngoscope 115, 191-204.

Ostapoff, E. M., Feng, J. J., and Morest, D. K. (1994). A physiological and structural study of neuron types in the cochlear nucleus. II. Neuron types and their structural correlation with response properties. J. Comp. Neurol. 346, 19-42.

Petralia, R. S., Esteban, J. A., Wang, Y. X., Partridge, J. G., Zhao, H. M., Wenthold, R. J., and Malinow, R. (1999). Selective acquisition of AMPA receptors over postnatal development suggests a molecular basis for silent synapses. Nat. Neurosci. 1, 31-36.

Petursdottir, G. (1990). Vestibuloocular projections in the 11-day chicken embryo, pathway specificity. J. Comp. Neurol. 297, 283-297.

Peusner, K. D. (1984). The development of synapses and "spoon" synaptic terminal space in the tangential vestibular nucleus: a quantitative electron microscope study. J. Comp. Neurol. 230, 372-385.

Peusner, K. D., and Giaume, C. (1994). The first developing "mixed" synapses between vestibular sensory neurons mediate glutamate chemical transmission. Neuroscience 58, 99-113.

Peusner, K. D., and Giaume, C. (1997). Ontogeny of electrophysiological properties and dendritic pattern in second-order chick vestibular neurons. J. Comp. Neurol. 384, 621-633.

Peusner, K. D., and Morest, D. K. (1977). The neuronal architecture and topography of the nucleus vestibularis tangentialis in the late chick embryo. Neuroscience 2, 189-207.

Popratiloff, A., and Peusner, K. D. (2007). Otolith fibers and terminals in chick vestibular nuclei. J. Comp. Neurol. 502, 19-37.

Popratiloff, A., and Peusner, K. D. (2011). GABA and glycine immunolabeling in the chicken tangential nucleus. Neuroscience 175, 328-343.

Popratiloff, A., Wang, Y. X., Narvid, J., Petralia, R. S., Giaume, C., and Peusner, K. D. (2004). AMPA receptor subunit expression in chick vestibular nucleus neurons. J. Neurosci. Res. 76, 662-677.

Precht, W. (1986). Recovery of some vestibuloocular and vestibulospinal functions following unilateral labyrinthectomy. Prog. Brain Res. 64, 381-389.

Precht, W., Shimazu, H., and Markham, C. H. (1966). A mechanism of central compensation of vestibular function following hemilabyrinthectomy. $J$ Neurophysiol. 29, 996-1010.

Ris, L., Capron, B., de Waele, C., Vidal, P.-P., and Godaux, E. (1997). Dissociations between behavioral recovery and restoration of vestibular activity in the unilabyrinthectomized guinea-pig. J. Physiol. 500, 509-522.

Rogers, L. J. (1995). The Development of Brain and Behavior in the Chicken. Wallingford: CAB International Press.

Romand, S., Wang, Y., ToledoRodriguez, M., and Markram, H. (2011). Morphological development of thick-tufted layer $\mathrm{v}$ pyramidal cells in the rat somatosensory cortex. Front. Neuroanat. 5:5. doi:10.3389/fnana.2011.00005

Sadeghi, S. G., Goldberg, J. M., Minor, L. B., and Cullen, K. E. (2009). Efferentmediated responses in vestibular nerve afferents of the alert macaque. J. Neurophysiol. 101, 988-1001.

Sadeghi, S. G., Minor, L. B., and Cullen, K. E. (2010). Neural correlates of motor learning in the vestibulo-ocular reflex, dynamic regulation of multimodal integration in the macaque vestibular system. J. Neurosci. 30, 10158-10168.

Sadeghi, S. G., Minor, L. B., and Cullen, K. E. (2011). Multimodal integration after unilateral labyrinthine lesion, single vestibular nuclei neuron responses and implications for postural compensation. J. Neurophysiol. 105, 661-673.

Schaefer, K. P., and Meyer, D. L. (1981). "Aspects of vestibular compensation in the guinea pig," in Lesion-induced neuronal plasticity in sensorimotor systems, eds H. Flohr and W. Precht (New York: Springer-Verlag), 197-207.

Sekirnjak, C., and du Lac, S. (2006). Physiological and anatomical properties of mouse medial vestibular nucleus neurons projecting to the oculomotor nucleus. J. Neurophysiol. 95, 3012-3023.

Sekirnjak, C., Vissel, B., Bollinger, J., Faulstich, M., and du Lac, S. (2003). Purkinje cell synapses target physiologically unique brainstem neurons. J. Neurosci. 23, 6392-6398.

Serafin, M., de Waele, C., Khateb, A., Vidal, P. P., and Muhlethaler, M. (1991a). Medial vestibular nucleus in the guinea-pig. I. Intrinsic membrane properties in brainstem slices. Exp. Brain Res. 84, 417-425.
Serafin, M., de Waele, C., Khateb, A., Vidal, P. P., and Muhlethaler, M. (1991b). Medial vestibular nucleus in the guinea-pig. II. Ionic basis of the intrinsic membrane properties in brainstem slices. Exp. Brain Res. 84, 426-433.

Shao, M., Gottesman-Davis, A., Popratiloff, A., and Peusner, K. D. (2008). Dye coupling in developing vestibular nuclei. J. Neurosci. Res. 86, 832-844.

Shao, M., Hirsch, J. C., Giaume, C., and Peusner, K. D. (2003). Spontaneous synaptic activity is primarily GABAergic in vestibular nucleus neurons of the chick embryo. J. Neurophysiol. 90, 1182-1192.

Shao, M., Hirsch, J. C., Giaume, C. and Peusner, K. D. (2004). Spontaneous synaptic activity in chick vestibular nucleus neurons during the perinatal period. Neuroscience 127, 81-90.

Shao, M., Hirsch, J. C., and Peusner, K. D. (2006a). Maturation of firing pattern in chick vestibular nucleus neurons. Neuroscience 141 , 711-726.

Shao, M., Hirsch, J. C., and Peusner, K. D. (2006b). Emergence of action potential generation and synaptic transmission in vestibular nucleus neurons. J. Neurophysiol. 96, 1215-1226.

Shao, M., Hirsch, J. C., and Peusner, K. D. (2012). Plasticity of spontaneous excitatory and inhibitory synaptic activity in morphologically-defined vestibular nuclei neurons during early vestibular compensation. J. Neurophysiol. 107, 29-41.

Shao, M., Popratiloff, A., Yi, J., Lerner, A., Hirsch, J. C., and Peusner, K. D. (2009). Adaptation of chicken vestibular nucleus neurons to unilateral vestibular ganglionectomy. Neuroscience 161, 988-1007.

Shao, M., Reddaway, R., Hirsch, J. C., and Peusner, K. D. (2011) "Changes in presynaptic and postsynaptic GABAB receptors in vestibular nuclei neurons during early vestibular compensation," in 2011 Society for Neuroscience Annual Meeting, Washington, DC.

Sirkin, D. W., Precht, W., and Courjon, J. H. (1984). Initial, rapid phase of recovery from unilateral vestibular lesion in rat not dependent on survival of central portion of vestibular nerve. Brain Res. 302, 245-256.

Smith, P. F., and Curthoys, I. S. (1989). Mechanisms of recovery following unilateral labyrinthectomy: a review. Brain Res. Brain Res. Rev. 14, 155-180.

Spencer, R. F., Wenthold, R. J., and Baker, R. (1989). Evidence for glycine as an inhibitory neurotransmitter of vestibular, reticular, and prepositus hypoglossi neurons that project to the cat abducens nucleus. J. Neurosci. 9, 2718-2736.

Spiegel, E. A., and Demetriades, T. D. (1925). Die zentrale compensation des labyrinth verlusters. Pflugers Arch. Gesamte Physiol. 210 215-222.

Straka, H., and Dieringer, N. (1993). Electrophysiological and pharmacological characterization of vestibular inputs to identified frog abducens motoneurons and internuclear neurons in vitro. Eur. J. Neurosci. 5 , 251-260.

Straka, H., Holler, S., and Goto, F (2002). Patterns of canal and otolith afferent input convergence in frog second-order vestibular neurons. J. Neurophysiol. 88, 2287-2301.

Straka, H., Vibert, N., Vidal, P. P., Moore, L. E., and Dutia, M. B. (2005). Intrinsic membrane properties of vertebrate vestibular neurons, function, development and plasticity. Prog. Neurobiol. 76, 349-392.

Sun, Y., Godfrey, D. A., and Rubin, A. M. (2002). Plasticity of gammaaminobutyrate receptors in the medial vestibular nucleus of rat after inferior cerebellar peduncle transection. J. Vestib. Res. 12, 1-14.

Takazawa, T., Saito, Y., Tsuzuki, K., and Ozawa, S. (2004). Membrane and firing properties of glutamatergic and GABAergic neurons in the rat medial vestibular nucleus. J. Neurophysiol. 92, 3106-3120.

Tighilet, B., Brezun, J. M., Sylvie, G. D., Gaubert, C., and Lacour, M. (2007). New neurons in the vestibular nuclei complex after unilateral vestibular neurectomy in the adult cat. Eur. J. Neurosci. 25, 47-58.

Vibert, N., Beraneck, M., Bantikyan, A., and Vidal, P. P. (2000). Vestibular compensation modifies the sensitivity of vestibular neurones to inhibitory amino acids. Neuroreport 11, 1921-1927.

Vibert, N., Serafin, M., Vidal, P. P., and Muhlethaler, M. (1995). Effects of baclofen on medial vestibular nucleus neurones in guinea-pig brainstem slices. Neurosci. Lett. 183, 193-197.

Wallman, J., Velez, J., Weinstein, B., and Green, A. E. (1982). Avian vestibuloocular reflex: adaptive plasticity 
and developmental changes. J. Neurophysiol. 48, 952-967.

Wilson, V. J., and Maeda, M. (1974). Connections between semicircular canals and neck motorneurons in the cat. J. Neurophysiol. 37, 346-357.

Wojcik, W. J., and Neff, N. H. (1984). Gamma-aminobutyric acid B receptors are negatively coupled to adenylate cyclase in brain, and in the cerebellum these receptors may be associated with granule cells. Mol. Pharmacol. 25, 24-28.

Wold, J. E. (1978). The vestibular nuclei in the domestic hen (Gallus domesticus), ascending projections to the mesencephalic eye motor nuclei. $J$. Comp. Neurol. 179, 393-406.
Yamanaka, T., Him, A., Cameron, S. A., and Dutia, M. B. (2000). Rapid compensatory changes in GABA receptor efficacy in rat vestibular neurons after unilateral labyrinthectomy. J. Physiol. 523, 413-424.

Zhang, R., Ashton, J., Horii, A., Darlington, C. L., and Smith, P. F. (2005). Immunocytochemical and stereological analysis of $\mathrm{GABA}(\mathrm{B})$ receptor subunit expression in the rat vestibular nucleus following unilateral vestibular deafferentation. Brain Res. 1037, 107-113.

Zhou, F. W., Chen, H. X., and Roper, S. N. (2009). Balance of inhibitory and excitatory synaptic activity is altered in fast-spiking interneurons in experimental cortical dysplasia. $J$. Neurophysiol. 102, 2514-2525.

Zhu, J. J. (2009). Activity leveldependent synapse-specific AMPA receptor trafficking regulates transmission kinetics. J. Neurosci. 29, 6320-6335.

Conflict of Interest Statement: The authors declare that the research was conducted in the absence of any commercial or financial relationships that could be construed as a potential conflict of interest.

Received: 05 December 2011; accepted: 27 January 2012; published online: 20 February 2012.
Citation: Peusner KD, Shao $M$, Reddaway R and Hirsch JC (2012) Basic concepts in understanding recovery of function in vestibular reflex networks during vestibular compensation. Front. Neur. 3:17. doi: 10.3389/fneur.2012.00017

This article was submitted to Frontiers in Neuro-otology, a specialty of Frontiers in Neurology.

Copyright (c) 2012 Peusner, Shao, Reddaway and Hirsch. This is an open-access article distributed under the terms of the Creative Commons Attribution Non Commercial License, which permits noncommercial use, distribution, and reproduction in other forums, provided the original authors and source are credited. 